\title{
The Circular Business Framework for Building, Developing and Steering Businesses in the Circular Economy
}

\author{
Julian Lauten-Weiss * (D) and Stephan Ramesohl \\ Wuppertal Institute for Climate, Environment and Energy, Döppersberg 19, 42103 Wuppertal, Germany; \\ stephan.ramesohl@wupperinst.org \\ * Correspondence: Julian.LautenWeiss@gmail.com
}

\section{check for} updates

Citation: Lauten-Weiss, J.; Ramesohl, S. The Circular Business Framework for Building, Developing and Steering Businesses in the Circular Economy. Sustainability 2021, 13, 963. https://doi.org/10.3390/su13020963

Received: 15 December 2020

Accepted: 13 January 2021

Published: 19 January 2021

Publisher's Note: MDPI stays neutral with regard to jurisdictional claims in published maps and institutional affiliations.

Copyright: (c) 2021 by the authors. Licensee MDPI, Basel, Switzerland. This article is an open access article distributed under the terms and conditions of the Creative Commons Attribution (CC BY) license (https:// creativecommons.org/licenses/by/ $4.0 /)$.

\begin{abstract}
The need for a transition towards a circular economy (CE) is evident, as the current economic model is based on the exploitation of far more resources than the planet can replenish sustainably. A significant part of this economic transition is the inception of new, CE-oriented startups and business activities. While business model frameworks (BMF), such as the Business Model Canvas (BMC), were at the center of discussions about structuring business ideas in the beginning of the millennium, the conversation must now shift towards circular BMFs (CBMF). This paper follows the Design Research Methodology (DRM) for an empirical approach to devising a novel CBMF, including expert interviews as well as a first application of the framework with a startup. Throughout this process, a new and innovative tool called Circular Business Framework (CBF) was created and tested based on CE principles.
\end{abstract}

Keywords: circular economy; entrepreneurship; business model framework; management tools; sustainable business model innovation

\section{Introduction}

The transformation towards a climate-friendly, resource-efficient circular economy (CE) is increasingly gaining momentum. A growing number of national as well as supranational governing bodies such as the European Union are developing strategies and action plans for transforming their respective economies accordingly [1-5], and a committee to define common standards and frameworks for the Circular Economy was formed by the International Organization for Standardization (ISO) in 2018 and announced in 2019 [6]. In the meantime, the European Investment Bank is planning to become "The EU Climate Bank" [7] and companies are racing to secure a share of the growing market in areas like renewable energy and "green tech" [8].

A misconception more commonly found in earlier definitions of the $\mathrm{CE}$, is that it can be summed up just by the phrase "reduce, reuse, recycle" [9]. However, this paper aims to clearly distinguish between these basic circular business strategies (CBS), as seen in previous works on circular business models (CBM) [10,11], and a more abstract view of "how an organization creates, delivers and captures value." [12]. Figure 1 shows a model of the CE that includes the frequently used "set of R's" as CBS for retaining value at the core, while also featuring complementing aspects such as eco-design as well as material and energy flows.

Amongst businesses across all industries, there is a growing understanding of sustainability as a commercial opportunity and a strategic priority [13]. Such a shift requires companies to rethink their business models to secure their long-term success. However, a study about barriers to the CE identified a "hesitant company culture" (p. 268) as one of the main obstacles. In many firms, CE often is restricted to a corporate social responsibility function, and therefore has "much less appeal in more influential departments such as operations or finance" [14]. Another study shows the other side of the same coin by identifying culture as the main enabler for a CE [15]. 


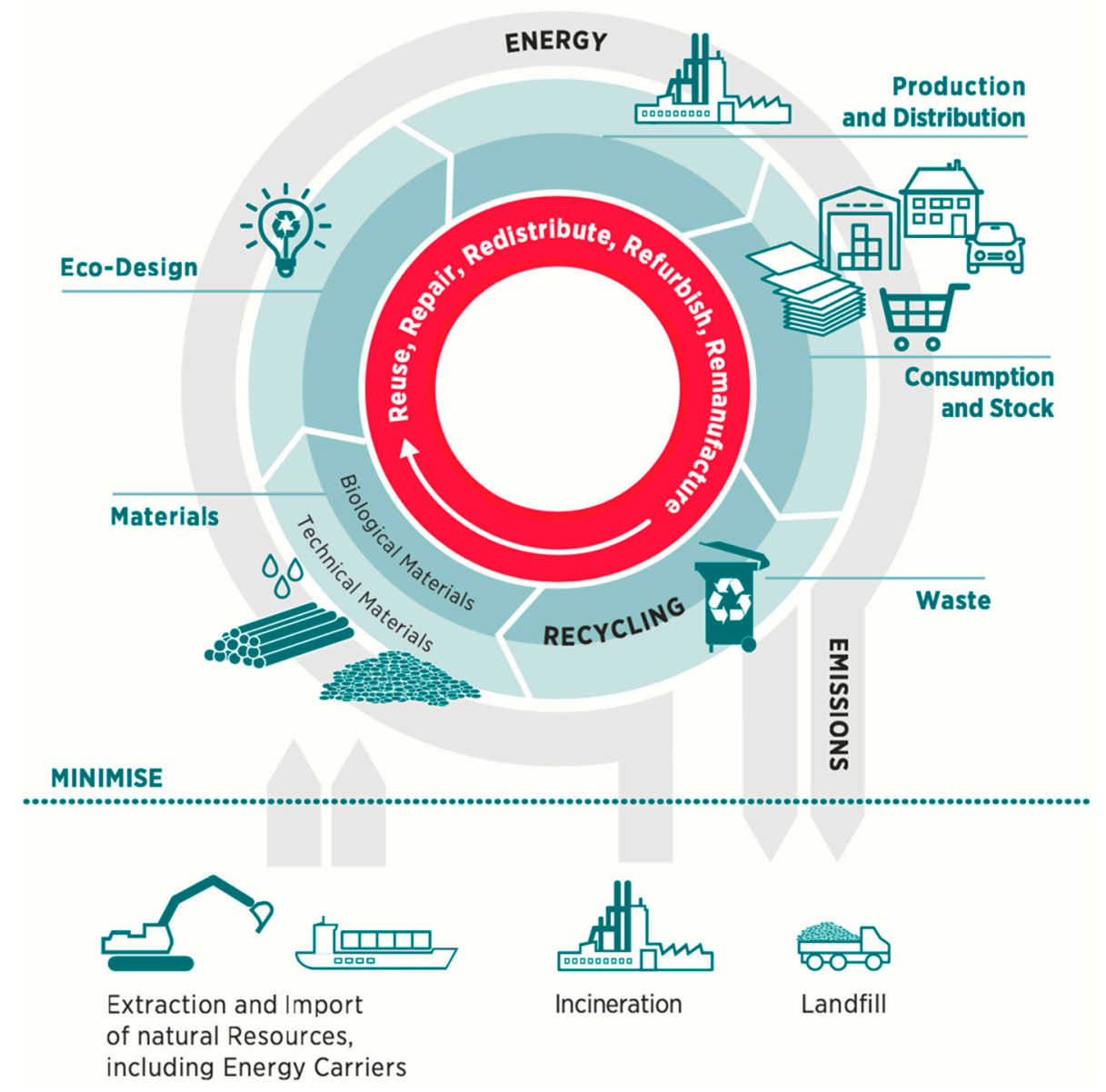

Figure 1. A simplified model of the circular economy ([16] based on [17]).

To address this, business model (BM) innovation can help to shift the strategic direction of a business to be more compatible with existing or emerging market conditions [18]. Bocken et al. (2014) defined BM innovations for sustainability as: "Innovations that create significant positive and/or significantly reduced negative impacts for the environment and/or society, through changes in the way the organisation and its value-network create, deliver value and capture value (i.e., create economic value) or change their value propositions." [19]. One tool for ensuring such anchoring of the CE in every component of the business model (BM) can be a circular business model framework (CBMF). In recent years, several attempts to create such CBMFs have been made, but all of them are adaptations of the Business Model Canvas (BMC) by Osterwalder and Pigneur-leaving room for new attempts at devising a CBMF built on CE principles (the three CE principles promoted by the Ellen MacArthur Foundation are: (1) Design out waste and pollution, (2) keep products and materials in use and (3) regenerate natural systems [20]) instead of revising an established (linear) BMF to fulfill the "need for a comprehensive conceptual framework for the circular business model" [21].

In this context, a BMF may represent a success-critical tool for companies, especially in an early stage. A research group analyzing the reasons why over 200 startups failed found that over a third (35\%) of them did not succeed because they had a "wrong" BM or were missing an explicit one altogether [22]. Therefore, albeit simplified and generalized to some degree, a BMF is useful, as it can serve as a tool for structuring BMs and is essential for communicating with potential financiers [23]. By clarifying the underlying value proposition as well as the BM structure, a CBMF can bring real financial value to startups and businesses when faced with stakeholders that have difficulties understanding the value of CBMs [15]. 
The need for a new approach to devising a CBMF is highlighted in Section 2 when looking at previous attempts, neither of which offer the holistic redesign needed for the CE $[24,25]$. To incorporate a wide range of perspectives, the Design Research Methodology (DRM) was deployed in Section 3, allowing for a structured, empirical and iterative approach to designing a new type of CBMF [26]. Section 4 introduces the Circular Business Framework (CBF) for building, developing and steering businesses in the CE, followed by a discussion of the results in Section 5.

\section{Background}

\subsection{Business Models vs. Business Model Frameworks}

When searching for CBMFs, many papers about CBMs come up, detailing business practices that can bring a company more in line with CE principles $[10,11,27,28]$. These, however, can be better described as circular business strategies (CBS), as succinctly put by the director of the Center for Global Strategy and Governance at Haas School of Business, University of California, Berkeley: "A business model is more generic than a business strategy. Coupling strategy and business model analysis is needed to protect competitive advantage resulting from new business model design." [29]. An example for CBS frameworks is the Circular Strategies Scanner by Blomsma et al. (2019), offering one of the most comprehensive overviews of CE strategies [11]. However, it is mainly focused on a company's offering and does not address other aspects, such as finance, partners or customers that would typically be part of a BMF.

\subsection{Definition of Linear Business Model Frameworks}

As one of the most commonly used BMFs, the Business Model Canvas (BMC) by Osterwalder and Pigneur, has been used as a basis for analyzing and evaluating BMs for several years. Its components, commonly referred to as building blocks, are Key Partners, Key Activities, Key Resources, Value Proposition, Customer Relationship, Channels, Customer Segments, Cost Structure and Revenue Streams [12]. However, the BMC promotes little interaction between or change in its building blocks and portrays a static image [30], despite even the linear economy being dynamic. Another missing factor is the ecosystem [31], which is merely referenced by the blocks Key Partners and Customer Segments, but lacks depth and does not prompt users to consider the entire value chain of their products and services, as would be necessary to understand the overall environmental impact of a business' operations.

\subsection{Definition and Examples of Circular Business Model Frameworks}

In a paper about framing the research field of CBMs, a concise definition was given of what, in this paper, is referred to as a CBMF: "A circular business model is how a company creates, captures, and delivers value with the value creation logic designed to improve resource efficiency through contributing to extending useful life of products and parts [... ] and closing material loops." [32]. It becomes apparent that the general components of value creation, delivery and capture, as described by Osterwalder and Pigneur, are still applicable when adding circularity to a BMF. However, instead of only creating value from new resources and materials, the quality and longevity of products become value drivers themselves. Furthermore, value capture gets connected to value creation, thereby closing the loop. A CBMF should, therefore, include all components of a company's activities while simultaneously serving as a tool to structure business ideas in a way that helps to eliminate any negative impacts resulting both from internal processes and the complementary external ecosystem.

Table 1 summarizes recent attempts at creating a CBMF, underscoring the growing interest in the field. However, it also appears that only one of the depicted examples uses empirical approaches to investigate the essential elements required. On the contrary, all attempts rely entirely on the basic structure of the BMC by adopting all or most of its building blocks and renaming a few (e.g., Channels was changed to Distribution in the 
Circular Canvas). While the additional elements do shed a light on CE aspects, none offer a concrete overview of all relevant $\mathrm{CE}$ components, including the perspective of a dynamic ecosystem and embedded value chain, which are needed to enable truly circular product and material flows. Obviously, using a BMF designed for the linear economy as a starting point also bears the risk of falling into old patterns of linear BM design. These findings show largely similar results that do not manage to break out of the limitations inherent to the BMC. Therefore, a new approach, called Circular Business Framework, is offered in this paper, which has been developed through a multi-step design process involving several expert consultations as well as iterative testing.

Table 1. Review of recent circular business model frameworks (CBMFs).

\begin{tabular}{|c|c|c|c|c|c|}
\hline Name & Year & Methodology & $\begin{array}{c}\text { Number of } \\
\text { Business Model } \\
\text { Canvas (BMC) } \\
\text { Blocks }\end{array}$ & Additional Elements & Source \\
\hline $\begin{array}{c}\text { Flourishing } \\
\text { Business Canvas }\end{array}$ & 2015 & $\begin{array}{l}\text { Literature review, } \\
\text { interviews, case } \\
\text { studies }\end{array}$ & $7 / 9$ & $\begin{array}{ll}\text { - } & \text { Ecosystem services } \\
\text { - } & \text { Governance } \\
\text { - } & \text { Stakeholders } \\
\text { - } & \text { Ecosystem actors } \\
\text { - } & \text { Geeds } \\
\text { Goals }\end{array}$ & $\begin{array}{c}\text { [33] based on } \\
{[34,35]}\end{array}$ \\
\hline $\begin{array}{l}\text { Circular Business } \\
\text { Model Canvas }\end{array}$ & 2016 & Literature review & $9 / 9$ & $\begin{array}{ll}\text { - } & \text { Take-Back System } \\
\text { - } & \text { Adoption Factors } \\
\text { CE-related } \\
\text { sub-components, } \\
\text { including further } \\
\text { concepts and ideas }\end{array}$ & [21] \\
\hline $\begin{array}{c}\text { Business Model } \\
\text { Canvas }\end{array}$ & 2016 & None mentioned & $9 / 9$ & $\begin{array}{l}\text { - CE-related guiding } \\
\text { questions }\end{array}$ & [36] \\
\hline $\begin{array}{l}\text { Framework for } \\
\text { Sustainable } \\
\text { Circular Business } \\
\text { Model } \\
\text { Innovation }\end{array}$ & 2016 & Literature review & $9 / 9$ & $\begin{array}{ll}- & \text { Trends and drivers } \\
\text { - } & \text { Stakeholder involvement } \\
\text { - } & \text { Sustainability benefits } \\
\text { - } & \text { Sustainability } \\
& \text { requirements }\end{array}$ & [37] \\
\hline $\begin{array}{c}\text { Sustainable } \\
\text { Business Model } \\
\text { Canvas }\end{array}$ & 2018 & None mentioned & $9 / 9$ & $\begin{array}{ll}\text { - } & \text { Basic economic } \\
\text { sub-categories } \\
\text { - } & \text { Eco-Social Costs } \\
\text { - } & \text { Eco-Social Benefits }\end{array}$ & [38] \\
\hline Circular Canvas & 2019 & None mentioned & $7 / 9$ & $\begin{array}{ll}\text { - } & \text { Positive Impacts } \\
\text { - } & \text { Negative Impacts } \\
\text { - } & \text { Natural, Technical and } \\
& \text { Energy Resources } \\
\text { - } & \text { Next Use }\end{array}$ & [39] \\
\hline $\begin{array}{c}\text { Circular } \\
\text { Economy } \\
\text { Business Model } \\
\text { Framework }\end{array}$ & 2020 & None mentioned & $9 / 9$ & $\begin{array}{ll}- & \text { Value Shared } \\
- & \text { Systemic Benefits } \\
- & \text { Value Delivered } \\
\text { - } & \text { Offerings } \\
- & \text { Financing Options } \\
\text { - } & \text { CE-related guiding } \\
& \text { questions }\end{array}$ & [40] \\
\hline $\begin{array}{l}\text { A Business } \\
\text { Model Canvas } \\
\text { for the 21st } \\
\text { Century }\end{array}$ & 2020 & None mentioned & $7 / 9$ & $\begin{array}{ll}- & \text { Planet } \\
- & \text { Purpose } \\
- & \text { Community } \\
- & \text { Governance }\end{array}$ & {$[41]$} \\
\hline
\end{tabular}




\section{Design Research Methodology}

The Design Research Methodology (DRM) offers a useful approach to the research task because it "helps plan design research by providing process steps; and improves the chances of obtaining more valid and useful outcomes" [26] and has been adapted for various applications, including some specifically focused on the CE [11,42,43]. Figure 2 illustrates the different stages that led to the novel Circular Business Framework and that are further explained in the following sub-chapters.
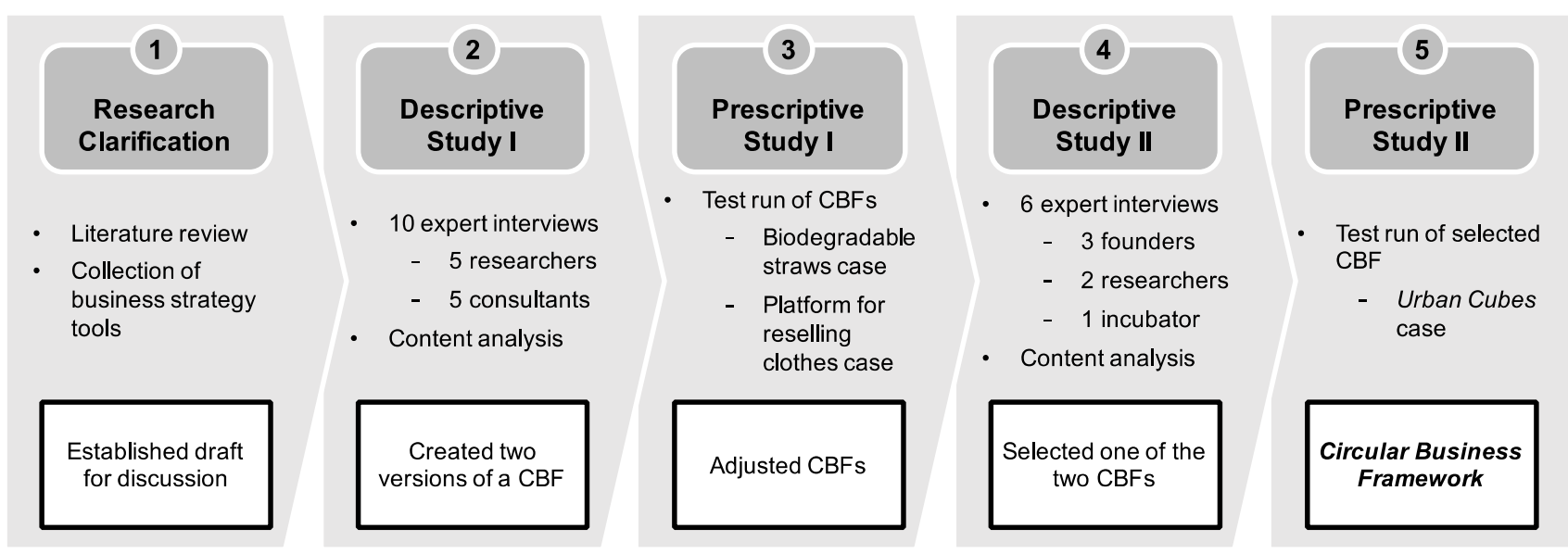

Figure 2. Schematic illustration of the creation of the Circular Business Framework showing each stage at the top, the main steps in the middle and results at the bottom.

\subsection{Research Clarification (RC)}

To gain a new perspective from the start, some basic strategy tools covering a variety of aspects have been considered. One of the main features the CBF introduces is the inclusion of a wider ecosystem, following the systems thinking practice of "zooming in" to highlight details and "zooming out" to show a larger perspective [44,45]. A first version of the "zoomed-in" perspective was based on the value chain by Michael E. Porter [46], while a first version of a "zoomed-out" ecosystem has been taken from the PESTEL analysis based on Francis J. Aguilar's book Scanning the Business Environment (1967). PESTEL is an acronym for a business' political, economic, social, technological, ecological and legal environment, which can help to cover multiple perspectives within the surrounding BM ecosystem [47]. Materials were also included, as seen in Figure 1, as well as data flows, which are important from a systems thinking perspective [48].

\subsection{Descriptive Study I (DS-I)}

Conducting expert interviews is recommended "when the literature review shows a lack of understanding about the chosen topic" [26]. This becomes evident when looking at the lack of new approaches to date, as evidenced by the heavy references to the BMC and subsequently similar outcomes. To test the CBF throughout the process, three sets of criteria were developed:

1. The three CE principles, since following them can lead to increased circularity;

2. "Zooming in and out", for a more holistic perspective that can help to understand the $\mathrm{CE}$ as well as support communication of the value/business case of a CE-oriented company;

3. Simplicity, clarity and usability, which contribute positively to communication overall.

The first round of interviews (the interviews took place digitally from 13 May to 1 June and lasted about $1 \mathrm{~h}$ on average) followed an inductive approach to collect a range of viewpoints and ideas on the elements that were synthesized into the first draft of the CBF. One half of the interviews were conducted with researchers and the other half with 
consultants who each have several years of practical experience in the field of sustainability and/or CE.

For the analysis of the results, an adaptation of Philipp Mayring's qualitative content analysis was chosen [49]. First, results were summarized and answer categories were formed, after which the responses were split up into the various categories. Then, the results were structured and distilled into two alternative versions due to the distinct approaches that emerged throughout the interviews, with one representing a process with different steps while the other took on a circular shape. Lastly, several components were added while others were removed due to explicit suggestions or simply a lack of attention paid to them.

\subsection{Prescriptive Study I (PS-I)}

The first Prescriptive Study (PS-I) stage of the DRM envisions some form of testing of the findings from the previous stage "to correct and elaborate on [ ... ] the desired situation." [26]. Three potential uses of the CBF in development were identified in this stage:

1. As a visual aid for communication, e.g., by helping investors quickly understand the $\mathrm{BM}$;

2. As a tool to structure ideas, e.g., by highlighting all areas of importance in a systematic manner;

3. As a guide to identify and measure CE impact, e.g., by pointing to the CE principles, encouraging the setting of one's own goals and metrics and keeping track of them from the start.

From these findings, key requirements for the CBF can be derived: First, it should be visually appealing and easy to understand. Second, it should be well-structured with clear directions for its use. Third, it should include CE principles (design out waste and pollution, keep products and materials in use, regenerate natural systems [20]) and ideas, as well as some direction on how to operationalize them.

The requirements as well as the functionality of the two alternative versions resulting from the previous step have been tested, with two simple, exemplary cases (the testing took place on 21 June, with a fictional startup looking to sell biodegradable straws for the first version and a new platform for reselling clothes for the second version. Each iteration took roughly $2 \mathrm{~h}$.). This showed that it was possible to come up with plausible answers to almost all components in the frameworks and that both alternatives provoked new ideas. The CE principles led to reflection on how the BM under development would be able to support them. Lastly, guiding questions were drafted to further fulfil the requirements listed above. The use case testing of both versions of the novel CBF resulted in further alterations, such as conceptual reorganization and bundling some components for simplicity and clarity.

\subsection{Descriptive Study II (DS-II)}

After evaluating the results of all previous stages, a second round of interviews was conducted with the aim of evaluating the CBFs with relevant stakeholders. The interviewees for this round were selected according to their involvement in the strategic development of circular businesses, with three of them having founded their own CEoriented startup (the interviews took place digitally from 30 June to 10 July, and lasted 50 min on average).

Again, answer categories were formed and filled out, with the interview results following Mayring's qualitative content analysis. Due to a small majority favoring the circle-shaped CBF, only this version was chosen for further development. All subsequent changes were made to improve clarity and usability from the point of view of the entrepreneurs and experts questioned in this stage. Each block was given a title under which all relevant components were grouped together, and guiding questions were added to each element, specifically referring to the CE principles whenever applicable, in addition to the overarching CE principles above the eight blocks. 


\subsection{Prescriptive Study II (PS-II)}

An additional PS stage was added to evaluate the material from the previous DSII stage in a practical application. To show the functionality and to uncover potential shortcomings of the new framework, a workshop with the two founders of the startup Urban Cubes was conceived (the workshop took place digitally on 10 July and lasted about $2.25 \mathrm{~h}$ ). The duration of one iteration was consistent with the results from the PS-I stage but, due to time constraints, a second iteration, albeit recommended, was not done in this case. Any feedback on the CBF was considered for the final version and some results from the workshop are presented in Section 5.

\section{Circular Business Framework}

This chapter introduces the Circular Business Framework (full size in Figure A1 in Appendix A), with each sub-chapter explaining one of the eight blocks, and closes with a practical case study. Figure 3 shows the full framework in the context of its supporting materials, which were designed to help in understanding and applying the framework as well as to present key takeaways.

\section{Understand the order of use}

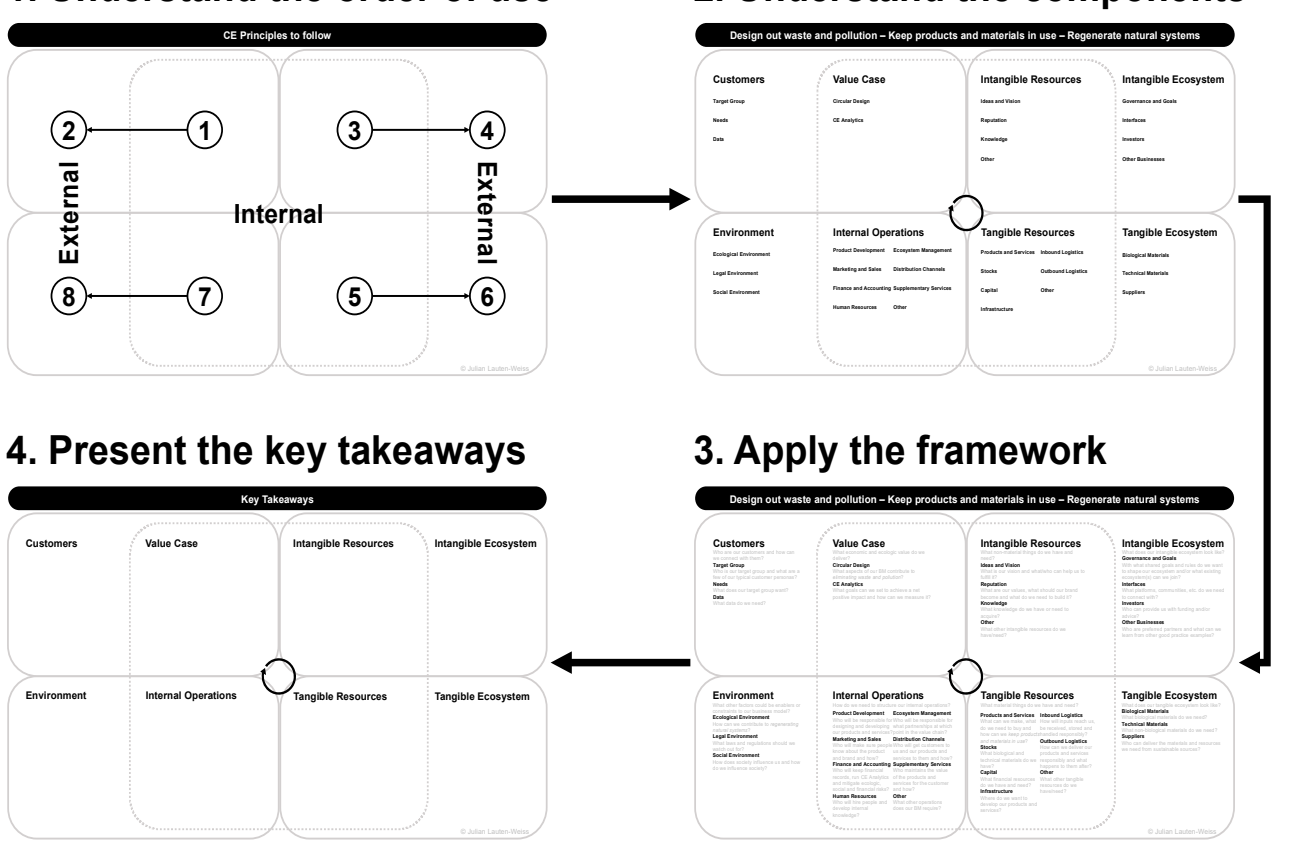

Figure 3. How to use the Circular Business Framework and its supporting materials.

When applying the framework to an initial idea for a new BM, at least two iterations are recommended to be able to reflect upon previous steps. The focus of the first iteration should be on collecting ideas and identifying open questions, while the second one should focus on developing the rationale and supporting evidence for a business case. Some time to reflect should be taken between iterations to collect feedback, answer open questions and to make the first calculations for a business case.

\subsection{Value Case}

Starting with an internally oriented block, the Value Case (See [50] for more information on the value case) addresses more conceptual aspects of the BM, much like the other blocks on the top row (blocks 1-4). The first component, Circular Design, focuses on the first CE principle and is aimed at setting the direction for further proceedings. The next component in this block is CE Analytics, where the user should collect some ideas for how to hold herself accountable when establishing the business. In the first iteration, it is not yet necessary to have a fully formed plan for how net positive environmental, social and 
financial impacts can be achieved. However, it is important to keep this in mind when working on the rest of the components.

\subsection{Customers}

In the first externally oriented block, the Target Group should be defined with a few thought-out examples for customers (personas), including their habits and preferences. Furthermore, Needs should be defined, and Data must be considered by listing any data that might be needed to learn more about the potential customers.

\subsection{Intangible Resources}

Block number three still focuses on the more conceptual aspects of the BM and again looks at the internal business perspective, where the entrepreneurs' Ideas and Vision should first be formulated. Next, Reputation encompasses the values for which the business should stand, what its brand should become, and what is needed to build it. Knowledge focuses on the expertise that is already available to the business and what additional knowledge or capabilities will have to be acquired. The last component, Other, can cover any other intangible resources available or needed.

\subsection{Intangible Ecosystem}

The next block should shed a light on the business' Intangible Ecosystem and starts with Governance and Goals, highlighting the importance of connecting with others and formulating a strategic framework for partnerships. The component Interfaces connects to the previous one and more concretely refers to any platforms, communities, etc., that the business should reach out to and connect with. Investors can be important for startups, but funding might not always be needed, which is why it can be beneficial to ask others to invest their time, knowledge and network, rather than just their money. Advice can also come from Other Businesses in the form of partnerships or by sharing good practice examples, which is why it is recommended to think about who could be preferred partners in the first iteration and to contact these people and organizations before the second iteration.

\subsection{Tangible Resources}

The counterpart to Intangible Resources begins to cover the more practical aspects in the bottom row (blocks 5-8) of the Circular Business Framework. The first component here is Products and Services, which includes a make-or-buy consideration for the products and services offered by the startup, as well as the second CE principle, encouraging the entrepreneur to extend the lifecycle of any material things as much as possible. Going with the theme of available and needed resources, Stocks of biological and technical materials should be listed, while financial resources should be considered under Capital. Infrastructure focuses on the location where the business operations take place and can include office spaces, production facilities, or even decentralized models of working. The components Inbound Logistics and Outbound Logistics revolve around ideas for handling inputs and outputs responsibly. The latter should, therefore, not only cover the logistics between the business and its customers, but also potential end-of-life-strategies for products and materials and related reverse logistics. Lastly, Other should include any other tangible resources that are available or needed.

\subsection{Tangible Ecosystem}

The Tangible Ecosystem differs from the Intangible Ecosystem in that it revolves around physical materials that are handled by the business in collaboration with external entities. The two components, Biological Materials and Technical Materials, should include any materials that are needed for business operations but are not yet included in Stocks. As a next step, Suppliers must be considered and should include, but not be limited to, aspects such as fair labor conditions, responsible agriculture and low-carbon business practices by suppliers. 


\subsection{Internal Operations}

How the firm is structured and run should be defined in this block, starting with Product Development, which links to Circular Design as well as Products and Services but focuses more on the specific role in the business. Marketing and Sales is linked to Reputation and should encompass the role that will develop a marketing strategy fit for the Customers. Another connected function is Finance and Accounting, which should include the quantification and measurement of risks related to unsustainable business practices, giving financial reasoning for the CBM. Human Resources is suggested to not only be the component defining who will hire people, but also who will take care of internal Knowledge development. Next, as an integral part of circular BMs, an Ecosystem Management role should be set up. Here, it could be useful to start mapping the value chain after a first iteration to understand relationships and potential gaps. Distribution Channels focuses on the person responsible for getting Customers to the business and the products and services to them. It is suggested that this role work closely with Marketing and Sales as well as Product Development to create the best fit between the offer and demand. Another related component is Supplementary Services, going beyond customer service in that it can also include quality controls as well as key account management. Any further operations that might be important for the BM can be listed under Other.

\subsection{Environment}

The eighth block of the framework, Environment, is partly practical and partly conceptual, and thereby serves as a connection from a first iteration back to the top row for a second iteration. Starting with the Ecological Environment, regenerating natural systems is especially worth considering if it is not possible to eliminate all emissions right away. In that case, offsetting by contributing to projects that help reduce or absorb emissions elsewhere becomes a temporary option for generating a net positive impact on the environment. The Legal Environment points to laws and regulations that may be subject to change in the dynamic field of CE and lastly, the Social Environment should include any initiatives for raising awareness of the CE as well as potential synergies with Marketing and Sales.

\subsection{Urban Cubes Case Study}

To show how the CBF may be used in practice, a first application was conducted with a young startup. Urban Cubes was founded in early 2020 by two entrepreneurs seeking to enter the urban gardening market in Germany. They view the trends towards organic and regionally grown food as well as greening cities as an opportunity to bring gardening to balconies in densely populated areas and to close nutrient cycles in cities. With their startup, they aim to reduce the collection and incineration of organic waste by reintroducing it into the soil in a decentralized way. This helps to regenerate natural systems and offers an organic sequestration of $\mathrm{CO}_{2}$ on the one hand, while creating hubs for biodiversity in cities and engaging people on a household level on the other, as "urban gardening connects humans in the most unnatural environment we created with what we need the most: nature and communities". To be as circular as possible, Urban Cubes plans to enable individual circular behavior through their products, which are produced in a modular way from as much reused and recycled material as possible. These products are then either sold or offered as a service, including a take-back scheme.

To test their BM and come up with new ideas for increasing their adherence to CE principles, the two founders agreed to using the Circular Business Framework in a provisional workshop setting. After one thorough iteration, they found the framework to be especially helpful during the early stages of BM development to structure ideas and identify gaps. Its design as well as the supporting materials were received positively, and the workshop yielded several impulses and ideas for optimizing their circular design as well as their material loops. All three requirements that were derived from the potential uses of the framework in Section 3.3 were addressed by the supporting materials as well as by the guiding questions, which were also received positively. Some (redacted) results from the 
application of the CBF during the workshop in the PS-II stage can be seen in Figure 4 using

the template for presenting key takeaways of the process.

\section{Key Takeaways}

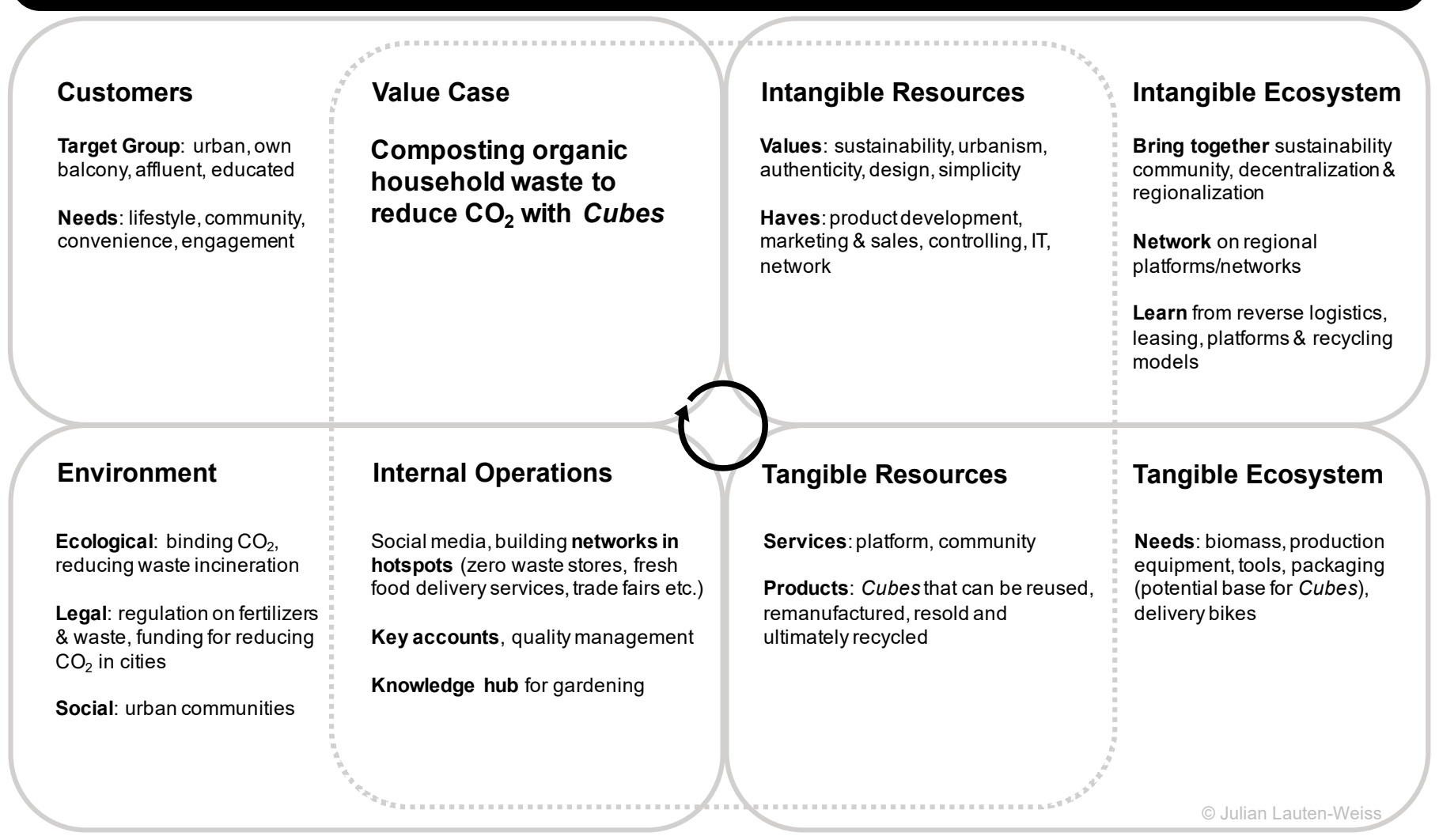

Figure 4. Urban Cubes Case.

\section{Discussion}

The concept of a Circular Economy (CE) has emerged as a prominent target picture for enhancing resource efficiency and lowering harmful emissions. The need for businesses to act and adapt their, to date predominantly linear business practices is widely recognized. CBMFs can support this shift, but previous attempts:

- Lack empirical approaches;

- Are based on the (linear) BMC, including its shortcomings

- Offer a limited view of the dynamic ecosystem surrounding a business.

By applying the DRM, the Circular Business Framework (full size in Figure A1 in Appendix A) was created as an extensive guide for structuring BMs while guiding the user towards more circularity. A significant conceptual difference is the explicit alternation between an internal and external perspective, still following a continuous logic from conceptual to more practical blocks. Additionally, the ecosystem perspective reveals external elements that are not under the direct control of the business, but have been included systematically. It also offers far more elements than most CBMFs without compromising on its usability. This might add some complexity, but the level of detail, coupled with guiding questions, can also be an advantage, even for users with advanced knowledge about business and the $\mathrm{CE}$, as shown in the Urban Cubes case. For established companies, the CBF can give some initial guidance on how to improve their adherence to CE principles and strengthen their circularity.

A limitation of the methodology applied is its qualitative nature, opening itself to some bias introduced by the authors. It should be stressed that this work represents 
an exploratory study that could be complemented by quantitative studies or a larger qualitative scope. Further research could test the CBF with a range of businesses regarding its short-term usability and its long-term support in achieving circular and financial success. Another worthwhile endeavor would be creating metrics for quantifying the business' CE impact and finding links to financial risks and benefits.

Finally, more widely accepted definitions and concepts in the field of the CE have only recently started to emerge, limiting the theoretical foundation of the model. The relevant literature on the topic of CBMFs is still fragmented by different uses of the term 'business model' and diverse understandings of circularity, pointing to the need for stronger standardization of terminology within the scientific debate about the CE.

Author Contributions: J.L.-W. is the corresponding author of this manuscript. He contributed to the conceptualization, methodology, validation, data curation, analysis, visualization, writing and review. S.R. contributed to the conceptualization, validation, review, editing and supervision. All authors have read and agreed to the published version of the manuscript.

Funding: This research received no external funding. The authors acknowledge financial support by Wuppertal Institut für Klima, Umwelt, Energie gGmbH within the funding programme Open Access Publishing.

Institutional Review Board Statement: Not applicable.

Informed Consent Statement: Not applicable.

Data Availability Statement: The data presented in this study are available on request from the corresponding author. The data are not publicly available because the interviews were conducted in confidentiality.

Conflicts of Interest: The authors declare no conflict of interest. 


\section{Appendix A}

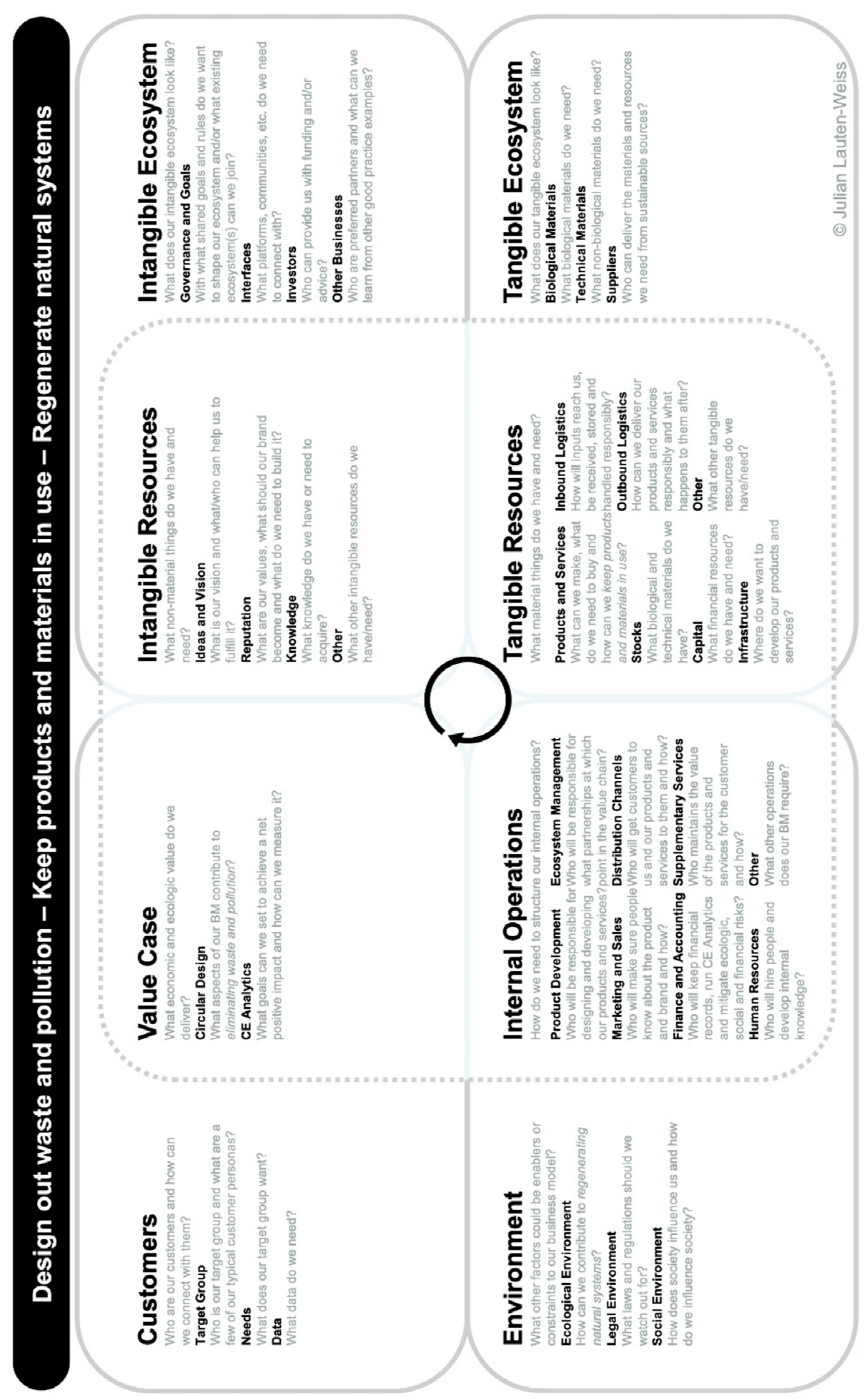

Figure A1. Circular Business Framework.

\section{References}

1. European Commission. A New Circular Economy Action Plan-For A Cleaner and More Competitive Europe; European Commission: Brussels, Belgium, 2020.

2. Weber, T.; Stuchtey, M. Pathways towards a German Circular Economy; Asatech: Munchen, Germany, 2019 ; p. 66. 
3. Department of the Environment, Climate and Communications. Climate Action and Environment A Waste Action Plan for a Circular Economy Ireland's National Waste Policy 2020-2025; Department of the Environment, Climate and Communications: Dublin, Ireland, 2020.

4. Arango, J.D.O.; Ramírez, R.V. Economía Circular PR IMER REPORTE 2020; Departamento Administrativo Nacional de EstadísticaDANE: Bogotá, Colombia, 2020.

5. Government Offices of Sweden. Sweden Transitioning to a Circular Economy. 2020. Available online: https://www.government. se/press-releases/2020/07/sweden-transitioning-to-a-circular-economy/ (accessed on 22 November 2020).

6. ISO/TC 323-Circular Economy. Available online: https://www.iso.org/cms/render/live/en/sites/isoorg/contents/data/ committee/72/03/7203984.html (accessed on 27 May 2020).

7. European Investment Bank. EIB Group Climate Bank Roadmap 2021-2025; European Investment Bank: Luxembourg, 2020.

8. Henzelmann, T.; Büchele, R.; Andrae, P.; Wiedemann, A. GreenTech Made in Germany 2018; Bundesministerium für Umwelt, Naturschutz und nukleare Sicherheit (BMU): Berlin, Germany, 2018; p. 208.

9. Kirchherr, J.; Reike, D.; Hekkert, M. Conceptualizing the Circular Economy: An Analysis of 114 Definitions. Resour. Conserv. Recycl. 2017, 127, 221-232. [CrossRef]

10. Lacy, P.; Keeble, J.; McNamara, R.; Rutqvist, J.; Eckerle, K.; Haglund, T.; Buddemeier, P.; Cui, M.; Sharma, A.; Cooper, A.; et al. Circular Advantage Innovative Business Models and Technologies to Create Value in a World without Limits to Growth; Accenture: Dublin, Ireland, 2014.

11. Blomsma, F.; Pieroni, M.; Kravchenko, M.; Pigosso, D.C.A.; Hildenbrand, J.; Kristinsdottir, A.R.; Kristoffersen, E.; Shahbazi, S.; Nielsen, K.D.; Jönbrink, A.-K.; et al. Developing a Circular Strategies Framework for Manufacturing Companies to Support Circular Economy-Oriented Innovation. J. Clean. Prod. 2019, 241, 118271. [CrossRef]

12. Osterwalder, A.; Pigneur, Y. Business Model Generation: A Handbook for Visionaries, Game Changers, and Challengers; Wiley: Hoboken, NY, USA, 2010; ISBN 978-0-470-87641-1.

13. Jørgensen, S.; Pedersen, L.J.T. RESTART Sustainable Business Model Innovation; Springer International Publishing: Cham, Switzerland, 2018; ISBN 978-3-319-91970-6.

14. Kirchherr, J.; Piscicelli, L.; Bour, R.; Kostense-Smit, E.; Muller, J.; Huibrechtse-Truijens, A.; Hekkert, M. Barriers to the Circular Economy: Evidence from the European Union (EU). Ecol. Econ. 2018, 150, 264-272. [CrossRef]

15. Rizos, V.; Behrens, A.; van der Gaast, W.; Hofman, E.; Ioannou, A.; Kafyeke, T.; Flamos, A.; Rinaldi, R.; Papadelis, S.; HirschnitzGarbers, M.; et al. Implementation of Circular Economy Business Models by Small and Medium-Sized Enterprises (SMEs): Barriers and Enablers. Sustainability 2016, 8, 1212. [CrossRef]

16. Wilts, H.; Berg, H. The Digital Circular Economy; Wuppertal Institute for Environment, Climate and Energy: Wuppertal, Germany, 2017; p. 7.

17. Reichel, A.; De Schoenmakere, M.; Gillabel, J. Circular Economy in Europe: Developing the Knowledge Base; European Environment Agency: Luxembourg, 2016; ISBN 978-92-9213-719-9.

18. Massa, L.; Tucci, C.L. Business Model Innovation. In The Oxford Handbook of Innovation Management; Oxford Handbooks; Dodgson, M., Gann, D., Phillips, N., Eds.; Oxford University Press: Oxford, UK, 2014; ISBN 978-0-19-969494-5.

19. Bocken, N.M.P.; Short, S.W.; Rana, P.; Evans, S. A Literature and Practice Review to Develop Sustainable Business Model Archetypes. J. Clean. Prod. 2014, 65, 42-56. [CrossRef]

20. Ellen MacArthur Foundation What Is a Circular Economy? Ellen MacArthur Foundation. Available online: https://www. ellenmacarthurfoundation.org/circular-economy/concept (accessed on 23 April 2020).

21. Lewandowski, M. Designing the Business Models for Circular Economy-Towards the Conceptual Framework. Sustainability 2016, 8, 43. [CrossRef]

22. Cantamessa, M.; Gatteschi, V.; Perboli, G.; Rosano, M. Startups' Roads to Failure. Sustainability 2018, 10, 2346. [CrossRef]

23. Bet, B.; Kas, J.; Truijens, D.; van der Lee, S.; Broere, J.; Leising, E.; Nuninga, T.; Bose, P.; van Ravensberg, E.; Di Francesco, E.; et al. Barriers and Best Practices for the Circular Economy SMO Promovendi-Circular Minds 2017/2018; Stichting Maatschappij en Onderneming (SMO): Rotterdam, The Netherlands, 2018.

24. Ellen MacArthur Foundation TOWARDS THE CIRCULAR ECONOMY Economic and Business Rationale for an Accelerated Transition; Ellen MacArthur Foundation: Cowes, UK, 2013.

25. Barreiro-Gen, M.; Lozano, R. How Circular Is the Circular Economy? Analysing the Implementation of Circular Economy in Organisations. Bus. Strat. Environ. 2020, 29, 3484-3494. [CrossRef]

26. Blessing, L.T.M.; Chakrabarti, A. DRM, A Design Research Methodology; Springer: London, UK, 2009; ISBN 978-1-84882-586-4.

27. Evans, J.L.; Bocken, N.M.P. A Tool for Manufacturers to Find Opportunity in the Circular Economy. In Proceedings of the International Conference on Sustainable Design and Manufacturing, Cardiff, Wales, UK, 28-30 April 2014.

28. Moreno, M.; De los Rios, C.; Rowe, Z.; Charnley, F. A Conceptual Framework for Circular Design. Sustainability 2016,8 , 937. [CrossRef]

29. Teece, D.J. Business Models, Business Strategy and Innovation. Long Range Plan. 2010, 43, 172-194. [CrossRef]

30. Sinkovics, N.; Sinkovics, R.R.; Yamin, M. The Role of Social Value Creation in Business Model Formulation at the Bottom of the Pyramid-Implications for MNEs? Int. Bus. Rev. 2014, 23, 692-707. [CrossRef]

31. Bocken, N.M.P.; Rana, P.; Short, S.W. Value Mapping for Sustainable Business Thinking. J. Ind. Prod. Eng. 2015, 32, 67-81. [CrossRef] 
32. Nußholz, J. Circular Business Models: Defining a Concept and Framing an Emerging Research Field. Sustainability 2017, 9, 1810. [CrossRef]

33. The Toolkit \& Canvas-Flourishing Enterprise Innovation Toolkit. Available online: https://flourishingbusiness.org/the-toolkitflourishing-business-canvas / (accessed on 1 January 2021).

34. Upward, A. Towards an Ontology and Canvas for Strongly Sustainable Business Models: A Systemic Design Science Exploration; York University: Toronto, ON, Canada, 2013.

35. Upward, A.; Jones, P. An Ontology for Strongly Sustainable Business Models: Defining an Enterprise Framework Compatible with Natural and Social Science. Organ. Environ. 2015, 29, 97-123. [CrossRef]

36. Ellen MacArthur Foundation. Business Model Canvas; Ellen MacArthur Foundation: Cowes, UK, 2016.

37. Antikainen, M.; Valkokari, K. A Framework for Sustainable Circular Business Model Innovation. Technol. Innov. Manag. Rev. 2016, 6, 8. [CrossRef]

38. CASE Sustainable Business Model Canvas. Available online: https://www.case-ka.eu/knowledge-platform/support/ sustainable-business-model-canvas / (accessed on 30 June 2020).

39. Circulab Circular Canvas. 2019. Available online: https://circulab.com/wp-content/uploads/2019/09/EN-Circular-CanvasCMJN.pdf (accessed on 3 April 2020).

40. Pieroni, M.P.; Jensen, T.H.; Pigosso, D.C.A.; McAloone, T.C. Circular Economy Business Modelling: CIRCit Workbook 2; Technical University of Denmark: Lyngby, Denmark, 2020; ISBN 978-87-7475-602-6.

41. Hilberts, B.-J.; Poulsen, S. A Business Model Canvas for the 21st Century. Available online: https://www.greenbiz.com/article/ business-model-canvas-21st-century (accessed on 3 April 2020).

42. Saidani, M.; Kim, H.; Cluzel, F.; Leroy, Y.; Yannou, B. Product Circularity Indicators: What Contributions in Designing for A Circular Economy? Proc. Des. Soc. Des. Conf. 2020, 10, 2129-2138. [CrossRef]

43. Hussaini, M. A Conceptual Model of Producer Mobility Support for Named Data Networking Using Design Research Methodology. IAENG Int. J. Comput. Sci. 2019, 46, 1-11.

44. Widmer, S. Design and the Circular Economy; KTH Industrial Engineering and Management: Stockholm, Sweden, 2016.

45. Zonnenshain, A.; Stauber, S. Managing and Engineering Complex Technological Systems; John Wiley Sons: Hoboken, NI, USA, 2015; ISBN 978-1-119-06846-4.

46. Porter, M.E. Competitive Advantage: Creating and Sustaining Superior Performance; The Free Press: New York, NY, USA, 1985.

47. Haaker, T.; Bouwman, H.; Janssen, W.; de Reuver, M. Business Model Stress Testing: A Practical Approach to Test the Robustness of a Business Model. Futures 2017, 89, 14-25. [CrossRef]

48. Meadows, D.H.; Wright, D. Thinking in Systems: A Primer; Earthscan: London, UK, 2009; ISBN 978-1-84407-726-7.

49. Mayring, P. Einführung in Die Qualitative Sozialforschung: Eine Anleitung Zu Qualitativem Denken; Pädagogik; 6., überarbeitete Auflage.; Beltz: Weinheim, Germany, 2016; ISBN 978-3-407-29452-4.

50. Dittrich, K.; Van Dijk, W. The Value Case Methodology. A Methodolgy Aligning Financial and Non-Financial Values in Large Multi-Stakeholder Innovation Projects. TNO 2013. [CrossRef] 